\title{
The Cultivation of Health Care Ability of College Students and the Research of Sports Intervention
}

\author{
Xiuying $\mathrm{Hu}^{1}$ \\ ${ }^{1}$ College of Physical Education, Qingdao University of Science and Technology, Qingdao, China \\ Correspondence: Xiuying Hu, College of Physical Education, Qingdao University of Science and Technology, \\ Qingdao, 266042, China. E-mail: xbsdhxy2003@163.com
}

Received: July 13, 2015 Accepted: November 9, 2015 Online Published: November 23, 2015

doi:10.5539/ass.v11n28p149 URL: http://dx.doi.org/10.5539/ass.v11n28p149

\begin{abstract}
By means of reference to literature, expert interviews, questionnaires others, with improving the health care ability of college students as the goal, from the perspective of sports curriculum intervention, the paper focuses the college students' various physiological and psychological pressure in this modern world, trying to find the positive role of the sports culture(P.E) in the development of health care ability of students, effective and workable strategies for sports intervention through the systematic research and exploration.
\end{abstract}

Keywords: college student, health care ability, sports intervention

\section{Introduction}

The "sub-health" is also known as "the third state of body", it could occur in any crowd, but the "sub-health" is especially prominent during the ordinary university students which are special crowd, it is also the most universal. As a result, how to train the ability of sports health care and consciousness of ordinary college students is very important. The cultivation of the concept of life-long health for the ordinary college students is imperative.

This paper revealed the status quo of ordinary colleges and universities students' health care ability, expounding its importance of the research, Analyzing its existing problems and reasons. The article formulated the corresponding effective intervention strategies and methods for the college students' health care ability, to make the ordinary university students after 90 cultivate the scientific and reasonable health and exercise habits to promote the college students' health index and the comprehensive ability of ascension. This also is the final purpose of this study.

\subsection{Research Objects}

The purpose of this study was to assess the effect of a curriculum intervention focuses in sports in the development of health care ability of students.

\section{Methods}

\subsection{Literature Review}

This topic has carried out research around the ordinary university students' ability of health care and sports intervention study and so on. The author reviewed the research results of at home and abroad in recent 10 years about sports keeping in good health care ability, sports intervention, Sports keeping in good health and the relevant discipline construction.

The author collected a large number of books, academic journals, the Internet search and related literature relating with the research purpose. We has carried on the theory of carding and discussed the relevant research, for example: the sports health care at home and abroad research on ability training and intervention of relevant theory combing, and so on, and we have combined with the development of the discipline of this major to analyze comprehensively. It could lay the good theoretical foundation for this subject research.

\subsection{Expert Interviews}

The authors through telephone access, personal visits, letter visits to some domestic and abroad experts and scholars who are mainly engaged in sports science, health science, health, psychology and other disciplines, and 
according to the theme of this subject and the object of study.

The authors have many details of the access for the ordinary university students' sports intervention of cultivating the ability of health care and other issues, and listening to the expert's advice and opinion. This is for the researchers to lay the good foundation.

We have 50 questionnaires, and recycling effective 50 questionnaires. The effective rate was $100 \%$. At the same time, we design the student questionnaire. We distribute student questionnaire, 250 in 5 colleges and universities, and recycling effective 226 questionnaires. The effective rate was $90.4 \%$.

\subsection{Questionnaire}

The authors have accorded to its theme of the subject and its object of study, to design the questionnaires. This topic is mainly oriented to Shan dong, Beijing, Tianjin, Shanghai and other four provinces of five colleges and universities. Namely, the authors went to Qingdao University of Science and Technology, Shandong Normal University, Beijing normal university, Tianjin Normal University, East China Normal University to the expert investigation, and got the relevant data.

At the same time, we also designed the student questionnaire, and to keep track of students who had taken part in the experiment, and obtained the relevant data.

\subsection{Experimental Method}

The authors have designed and implemented the experiment. They have a one year tracking survey of 86 students, grade 2012, at Qingdao University of Science \& Technology.

The research team selected the universal stronger health physical education curriculum to this research. And they designed three types of sports health curriculum interventional model according to the features of the project. They tracked investigation and research for different types of the intervention model. It applies to the changes of college students' health care and physiological and psychological and social adaptation ability. Trying to find out intervention model

of different sports and the health physical education. To study these models' influence for college students' health care ability, this helped the ordinary university sports health curriculum setting and implementation, and it also promoted the improvement of comprehensive health and ability of Chinese college students.

Trying to find the corresponding intervention strategies through experiments, physical fitness test for both the observation group and the control class, and got the analysis of the testing results and the corresponding conclusion. Finally the authors have discussed the corresponding scientific and reasonable intervention countermeasures for this topic.

\subsection{Mathematical Statistical Methods}

This article has Used SPSS, and SCL- 90 scale, and statistically analyzing the obtained survey data in a large of data.

\section{The Significance of the Cultivation of College Students' Health Care Ability in the New Era}

1) It is shown by the student physical test results that college students have their health problems to varying degrees. But more seriously, a lot of students are still in the feel-good- about- themselves state.

So, through this study, we must first let the students have a clear and correct understanding, pay real attention to their health problems and go a step further to practice sports intervention for the final purpose of improving physical fitness. Meanwhile for cultivating high quality talents, it will be of far reaching significance increasing the impact of health care in P.E

2) Contemporary social development has been expecting more of the ability of health care especially of the psychological health care ability and that to adapt to the society. That is to say, through the health care exercises, coupled with the intervention of sports characterized by some modern competition spirit, artistic temperament or teamwork, the improvement on the college students' comprehensive quality and their health care ability will surely be secured.

\section{The Analysis of the Status Quo about the Cultivation of College Student's Health Care Ability}

The author conducted questionnaire survey for the health care ability and health level of the different grade college students. The result shows that: (the Figure 1 and Table 1) 


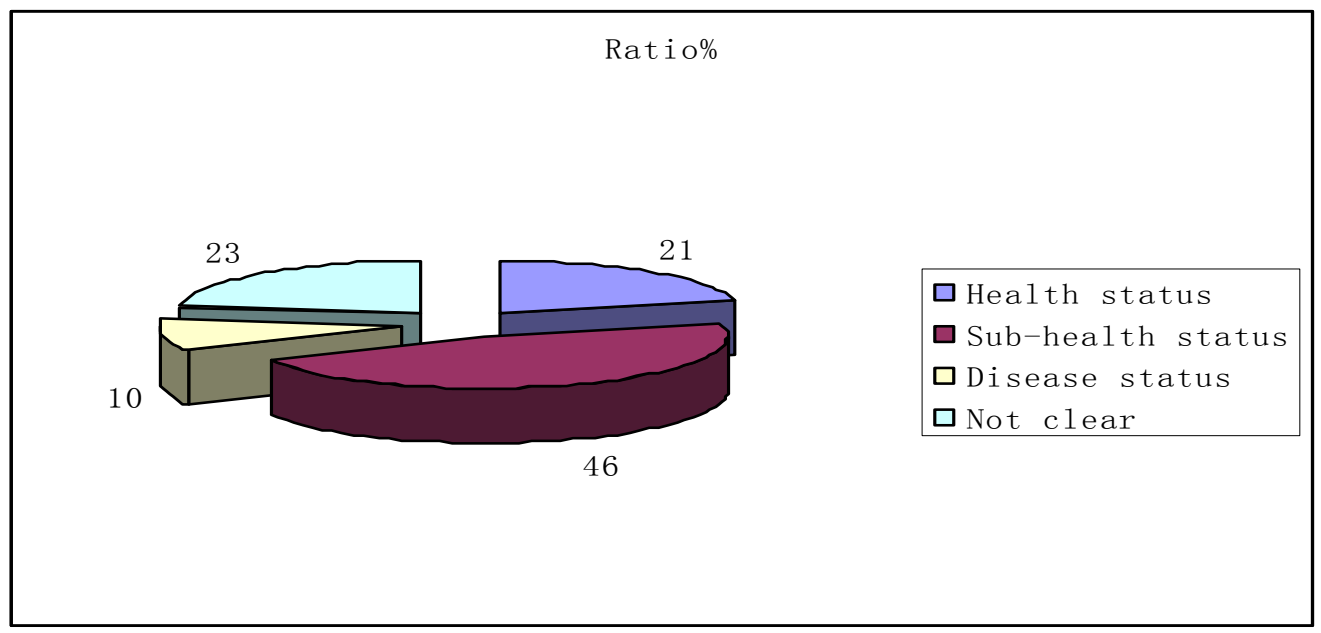

Figure 1. Contemporary college student's healthy index scale map

1) The Figure 1 shows that: College students' overall health is in the middle level and lower leveled is their social adaptation due to their poor physical health and mental health in particular. Therefore, the overall health level of college students is not in our favor, which, then, needs effective guidance and intervention from us educators.

2) The Figure 1 shows that: Although the new era of college students is the younger generation, but the proportion of health is only $17 \%$, "Sub-health" is $61 \%$, the "Unhealthy" disease states is $10 \%$, and even $12 \%$ of the people for their own health condition is not very clear. These only shows that the new era of college students lack scientific exercise attitude and regular way of life, they lack good health physical exercise habits.

It can be seen from Table 1: the height and weight of comparative classes is lower 0.15 points compared with experimental classes. It is important to show that, this gap is by sports intervention. Through the physical intervention, the students like more physical education classes and they participate in sports enthusiasm increased.

The other indicators showed a trend of rising, especially Physical quality overall score. The experimental classes are higher 6.42 scores than comparative classes. It is visible, physical intervention effect was very obvious.

In addition, with increasing social competition pressure, improper self-positioning and insufficient evaluation of their qualities, college students' mental capacity is getting from bad to worse. According to a survey those who drop out of school because of mental illness account for $54.4 \%$ in the total Figure of the dropouts. More the $30 \%$ of the students suffer from some psychological disease says the survey, and the Figure is increasing Two years or more for statement.

Thus, it is a must to carry out effective mental health guidance, and by exposing them to health care exercise, put them in a pleasant atmosphere of learning, let them acquire health care knowledge and skills, and finally enhance the psychological and physiological indexes.

Table 1. The contrast table of test indicators for experimental classes and comparative classes

\begin{tabular}{llll}
\hline The test content & Comparative classes & Experimental classes & Trend \\
\hline Height and weight & 18.82 & 18.67 & $\downarrow$ \\
Lung capacity & 11.93 & 12.82 & $\uparrow$ \\
sit and the body forward & 14.34 & 14.91 & $\uparrow$ \\
$50 \mathrm{~m}$ & 11.21 & 11.62 & $\uparrow$ \\
sit-ups & 9.85 & 10.62 & $\uparrow$ \\
$800 / 1000$ & 9.65 & 10.52 & $\uparrow$ \\
Standing long jump & 11.25 & 13.54 & $\uparrow$ \\
total score of physical fitness & 69.26 & 75.68 & $\uparrow$ \\
\hline
\end{tabular}


3) The poor health awareness, vulnerable health ability makes it very difficult for the college students to stay in health. Through the investigation and study showed that: The overall health care ability of ordinary university students is very poor, even no. The situation lets them who engaged in sports health research scholars, feel the largest pressure, Because of many reasons, during the ordinary university students: more than $90 \%$ college students lack the consciousness of self-health care, only $3.51 \%$, without prodding, conducting health evaluation or doing health exercise. So, in the four years of university life, especially in the first two years, the college sports is used as a compulsory course, the intervention is very necessary and important to improving the present situation through the sports health care course. (The Figure 2)

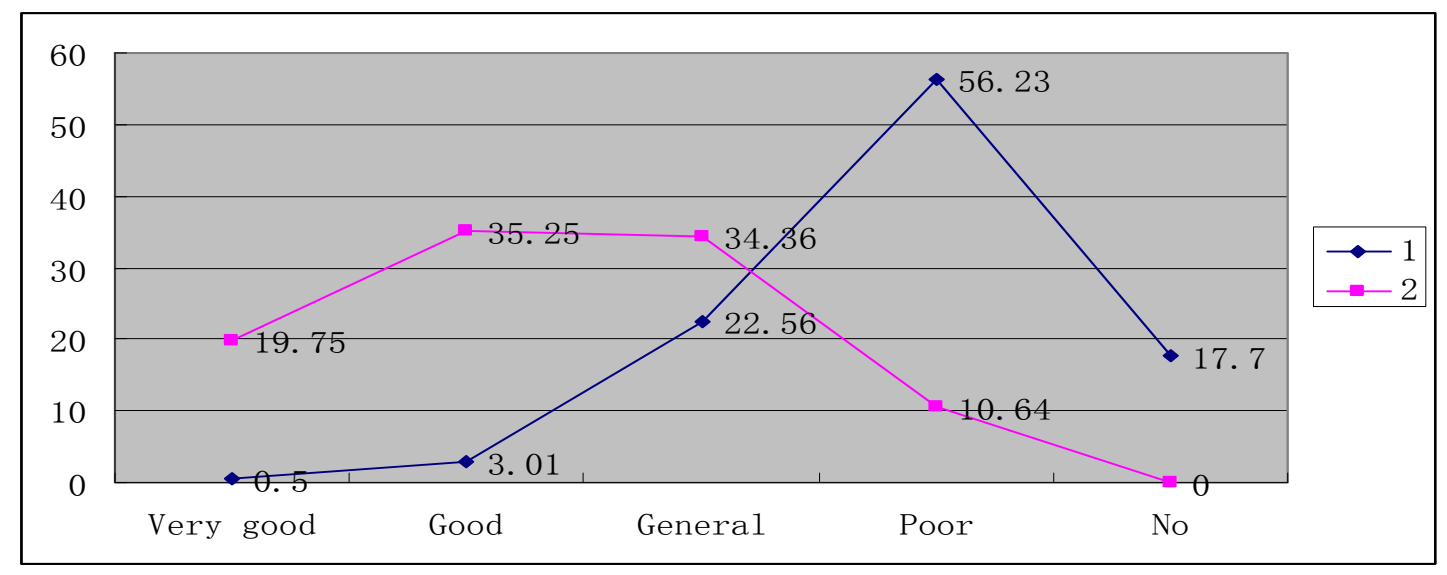

Figure 2. Sports keeping in good health care consciousness and ability of experimental classes and comparative classes

Notes. 1: comparative classes; 2: experimental classes.

First of all, under the guidance of teachers, students can be better adapted to their respective conditions and learning environment, better equipped with health care knowledge, get strong enough physiologically and psychologically to cope with a series of social problems to live a healthy and happy life .

Secondly, we could open some health care sports curriculum from the aspects of the course construction. For example, Taijiquan and Soft power ball and Baduanjin and Health care massage and Yijinjing and Wuqinxi and so on. It makes the students exercise, at the same time, they also master some health care movement methods and skills. And these movement forms closely linked to student's life, making the sports health care as a part of life for the college students, letting the sports health into daily life.

At the same time, they also learned how to maintain their body, how to adjust the psychological problem. The most important thing is that, these health care sports items which are full of traditional culture could gradually cultivate students' generous, kind and broad mind. So they could life and work in a friendly attitude.

\section{Findings and Countermeasures (The Table 2)}

Table 2. The compared table of students various aspects ability, sports keeping in good health care courses before and after the intervention

\begin{tabular}{lllllllll}
\hline $\begin{array}{l}\text { The } \\
\text { content }\end{array}$ & $\begin{array}{l}\text { Physical } \\
\text { quality } \\
\%\end{array}$ & $\begin{array}{l}\text { Exercise } \\
\text { habits } \%\end{array}$ & $\begin{array}{l}\text { Mental } \\
\text { health \% }\end{array}$ & $\begin{array}{l}\text { Diet and } \\
\text { nutrition } \\
\text { control } \\
\text { ability } \\
\%\end{array}$ & $\begin{array}{l}\text { Health } \\
\text { care } \\
\text { ability } \\
\%\end{array}$ & $\begin{array}{l}\text { Ability to } \\
\text { relate to } \\
\text { others } \\
\%\end{array}$ & $\begin{array}{l}\text { Social } \\
\text { adaptation } \\
\text { ability \% }\end{array}$ & $\begin{array}{l}\text { Self-health } \\
\text { evaluation \% }\end{array}$ \\
\hline 1 & 58.4 & 44.9 & 46.3 & 33.8 & 10.1 & 40.5 & 46.2 & 50.6 \\
2 & 72.5 & 83.2 & 78.9 & 84.5 & 64.2 & 79.2 & 78.4 & 78.6 \\
\hline
\end{tabular}

Notes. 1: Comparative classes; 2: Experimental classes. 
1) Strengthen the students' health care knowledge, improve their cognition of condition. By studying the data indicate that the experimental class and the control group are significant difference between summarization, Physical quality there is a significant difference, the mean difference of 14.1. The comprehensive physique of the former has improved to some extent, so has their endurance, flexibility confidence and the cognition of health.

Through the health care knowledge's popularization and accumulation, coupling with the students' continuous digestion, and taking part in Health care sports for a long time. The students' physical quality and health care consciousness and ability are indeed a different degree of improvement and improve.

In addition, cognition of the contrast group is still limited to feeling well or bad while the students in the test group, with the positive effect of sports intervention, may actively assess their health, improve their condition through exercise and psychological modulation. And this conclusively fully shows the sports intervention of health care does make a difference.

Among them, the comparative classes' proportion of health care ability is $10.1 \%$.And the experimental classes' proportion is increased to $64.1 \%$, increased by $54 \%$. This shows fully convincingly that health care sports intervention does play a role.

Therefore, the teaching process should be based on to the traditional health theory, with healthcare knowledge as it emphasis, "health first" as its principle, so that students can master the physiological, psychological and other related health knowledge, know the means and methods of physical exercise, and combine fitness with entertainment .

2) Strengthen students' abilities to adapt to society through healthcare exercise. Data show that, the interpersonal relationship in the experimental class is increased, the T value being $38.7 \%$. Students with the intervention of sports were more willing to cooperate with others for all tasks. Both their team cooperation ability and their adaptability to the society were improved. Their social adaptation ability is increased by $32.2 \%$. Healthcare exercise has the adaptability of the students to the social rhythm changes enhanced, and as a pastime, and lets off the problems brought with these fast rhythms, which is very important to personal health and social stability.

3) See that all students benefit from healthcare exercise, and embody the diversification and humanization of sports.

First of all, traditional health care project is a good choice for students of a wide range of interests because it is rich in content, not subject to site constraints, suitable for more people, and easy to develop and popularize. And the college students also could freely choose corresponding sports health sports exercise according to their own physical and psychological conditions.

Secondly, the students in different physical conditions can choose the corresponding events, to meet their needs of personality development. For those with physical disabilities or injuries students, the effect is more obvious.

After a year of health care sports intervention the indices observed of most of the subjects were significantly different from a year ago, their physical quality, mental health, the ability to relate to others and most indicators into significant difference, the students' psychological health index having improved significantly. These showed that, the students could improve their comprehensive health index through their own care and study hard, and the health index could obvious improvement.

4) Through intervention by practicing sports keeping in good health care, we could cultivate students' perfect personality.

It needed the hands, eyes, body, the method, footwork cooperation, during the process of practice. Their physiological and psychological aspects should also be timely to self-regulate. Therefore, it also could slowly ease tension, confusion and anxiety, etc. This is caused by the highly stressed work and study.

The experimental data show that: The experimental class is compared with comparative class, students' hostility and fear's $t$ value is different, the mental health increased 32.6 points, the experimental class's character would be kinder, through physical intervention.

For example, the students should firstly understand the cultural connotation of soft power ball, technical main point, during the process of practice. Secondly, it was to admire, the students should comprehend appreciate, recognition, appreciation, during the process of practice. Because of the different style of soft power ball would bring people's senses are not the same. So, the students could be more enjoying beauty. So, the panic and anxiety could change less, between people and people would be closer, harmonious. 


\section{Conclusion}

Sports intervention in health care can effectively reduce the psychological problems of contemporary college students, strengthen some indexes of physical quality, and improve the students' team work, adaptation to society, self-confidence and self-health care ability. Of course, in the concrete operation process, there are also many problems, such as the lack of teachers' health care knowledge and technical skills, less attention than enough to health care from the management, the lack of perfect relevant systems, all of which affect the otherwise effective process of sports intervention.

So, acquirement of teachers' professional knowledge as well as establishment of a comprehensive management system, and the joint efforts for intervention and guidance or counseling, from all relevant offices is required to prevent mental health problems from starving college students of healthy and happy lives.

\section{Acknowledgements}

Subject source: This article is the social science research fund project of Qingdao University of Science and Technology, 2011, the project number: 11XC30.

\section{References}

Hou, Z. H., Zhao, Q. S., \& Xu, C. J. (2007). The Experiment Research in the Physical Education Teaching by the Intervention Strategies for College Students' Mental Health. Journal of Gui zhou Normal University (Natural Sciences), (11), 118-119.

Li, Y. L. (2007). The Study on the Internal and External Factors of College Students' Physical Deterioration and the Intervention Measures of Colleges and universities sports curriculum. Journal of Guangzhou Sport University, (3), 105-107.

Liu, S. P., Fang, H., Yao, X. M., \& Xu, H. X. (2002). The Factors and Intervention Measures Which Effect on the physical ability situation of college freshmen. Practical preventive medicine, (8), 325-326.

Tang, W. J., \& Zhang, W. (2008). The Function of the College Students Physical Exercise Intervention Depression Analysis. Journal of Beijing Sport University, (11), 1534-1536.

Wan, J. (2009). The Intervention Strategy Research of Physical Exercise on Reading Graduate Students who Learn in Cheng Du Colleges and Universities. Journal of Chengdu Sport University, (8), 73-75.

Xu, F. Q., \& Wei, X. (1999).The Research on Traditional Health Care Courses and Disabled Students' Lifelong Exercise. Journal of Physical Education, (2), 42-44.

You, W. H., He, S., Cui, X. Y., \& Li, F. (2010). The Experimental Research by the Application of Exercise Prescription to Improve the Level of College Students' Physical and Mental Health. Fujian Sports Science and Technology, (6), 49-51.

Yuan, C. Z. (2005). A Research of the College Students' Psychological Health and Physical Education Intervention. Journal of Wuhan Institute of Physical Education, (1), 45-47.

Zhang, S. S., \& Tao, Y. (2006). The research of Health Status Quo of Some Medical College Students and Countermeasure of Physical Education Teaching Intervention. Journal of Guangzhou Institute of Physical Education, (7), 106-108.

Zhao et al. (2010). The Influence of Sports Intervention Measures for Higher Vocational Colleges Students of Physical Fitness and Health Effects. Journal of Lianyungang Technical College, (3), 59-60.

Zhao, X. D., \& Wang, K., Zhang, Y., \& Wang, J. B., \& Yu, R. A. (2008). The Phase Characteristics of the Mental Health of College Students and Sports Intervention. Journal of Beijing University of Physical Education, (5), 641-643.

Zhou, Z. L., \& Lu, Z. X., Wang, P. Y., Qiu, L. W., \& Liu, X. P. (2010). A Influence of Sports education on the psychological health of the medical college poverty students. Journal of Hai Nan Medical College, (2), 258-260.

\section{Copyrights}

Copyright for this article is retained by the author(s), with first publication rights granted to the journal.

This is an open-access article distributed under the terms and conditions of the Creative Commons Attribution license (http://creativecommons.org/licenses/by/3.0/). 